(NASA-TM-111214) STATISTICAL DESIGN IN ISOTHERMAL AGING OF POLYIMIDE RESINS (NASA. LeWIS Research (enter) $9 P$
N96-17348

Unclas

$63 / 27 \quad 0095136$ 


\title{
Statistical Design in Isothermal Aging of Polyimide Resins
}

\author{
JAMES K. SUTTER, ${ }^{1}$ J. MARCUS JOBE, ${ }^{2}$ and ElizABETH A. CRANE ${ }^{3}$ \\ 'Lewis Research Center, Cleveland, Ohio 44135, '²Miami University, Oxford, Ohio 45056, \\ and ${ }^{3}$ John Carroll University, Cleveland, Ohio 44118
}

\begin{abstract}
SYNOPSIS
Recent developments in research on polyimides for high temperature applications have led to the synthesis of many new polymers. Among the criteria that determines their thermal oxidative stability, isothermal aging is one of the most important. Isothermal aging studies require that many experimental factors are controlled to provide accurate results. In this article we describe a statistical plan that compares the isothermal stability of several polyimide resins, while minimizing the variations inherent in high-temperature aging studies. (C) 1995 John Wiley \& Sons, Inc.
\end{abstract}

\section{INTRODUCTION}

The NASA Lewis Research Center HITEMP program in polymer matrix composites (PMC) focuses on the development of high-temperature polymers for advanced aircraft engine fan and compressor applications. One of this program's main goals is to produce polymers that can withstand engine operating temperatures up to $425^{\circ} \mathrm{C}\left(800^{\circ} \mathrm{F}\right)$. Therefore, an important feature of these polymers is their thermal oxidative stability at high temperatures.

Several polymer matrix resins have been developed at NASA Lewis to meet these goals. PMR-II50 and VCAP-75 are two matrix resins that were investigated in engine component development programs. ${ }^{1,2}$ Additional resins developed at Lewis for high-temperature applications are N-CYCAP, 12FVCAP, 3F, and MARVimides. DuPont Company and TRW, Inc. have also developed resins for hightemperature applications. These resins are Avimid$\mathrm{N}$ (बi and AFR700B.

We report the findings of a study that we designed and analyzed with formal statistical methodologies. Specifically, the study was designed to compare, in a valid quantifiable manner, the respective weight losses among a selected set of five different resins after $400 \mathrm{~h}$ of exposure to high temperature $\left(371^{\circ} \mathrm{C}\right)$. The resins included in our investigation were

\footnotetext{
* To whom correspondence should be addressed. Journal of Applied Polymer Science, Vol. 57, 1491-1499 (1995) (C) 1995 John Wiley \& Sons, Inc. CCC 0021-8995/95/121491-09
}

Avimid-N, AFR700B, PMR-II-50, VCAP-75, and NCYCAP (Fig. 1).

Implementation of a statistically designed study allowed us to address the following two questions. Can we determine weight loss differences between these polymers? If so, how accurate are the estimated differences? The design for this study accounted for a location effect within the oven, and a molding powder or disk effect within a polymer. Two molding powders were available for PMR-II-50, VCAP-75, and N-CYCAP. One disk was produced from each of these powders. We obtained two disks from each resin developed by DuPont and TRW ( 2 Avimid-N disks and 2 AFR700B disks, respectively). Although the disks of Avimid-N came from a single batch of molding powder as did the disks of AFR700B, the molding powder-molding powder variability within a polymer was treated in the same way as the diskdisk variability within a polymer.

\section{EXPERIMENTAL}

\section{Instrumentation}

All infrared spectra were recorded with a Nicolet model 510P Fourier Transform Spectrometer in $\mathrm{KBr}$ pellets. All thermal analyses were recorded on a PL Thermal Sciences Thermal Analysis System. Thermogravimetric analyses were done with a PerkinElmer TGS-2 on postcured neat resin samples under air using a scan rate of $10^{\circ} \mathrm{C} / \mathrm{min}$. Thermomechan- 


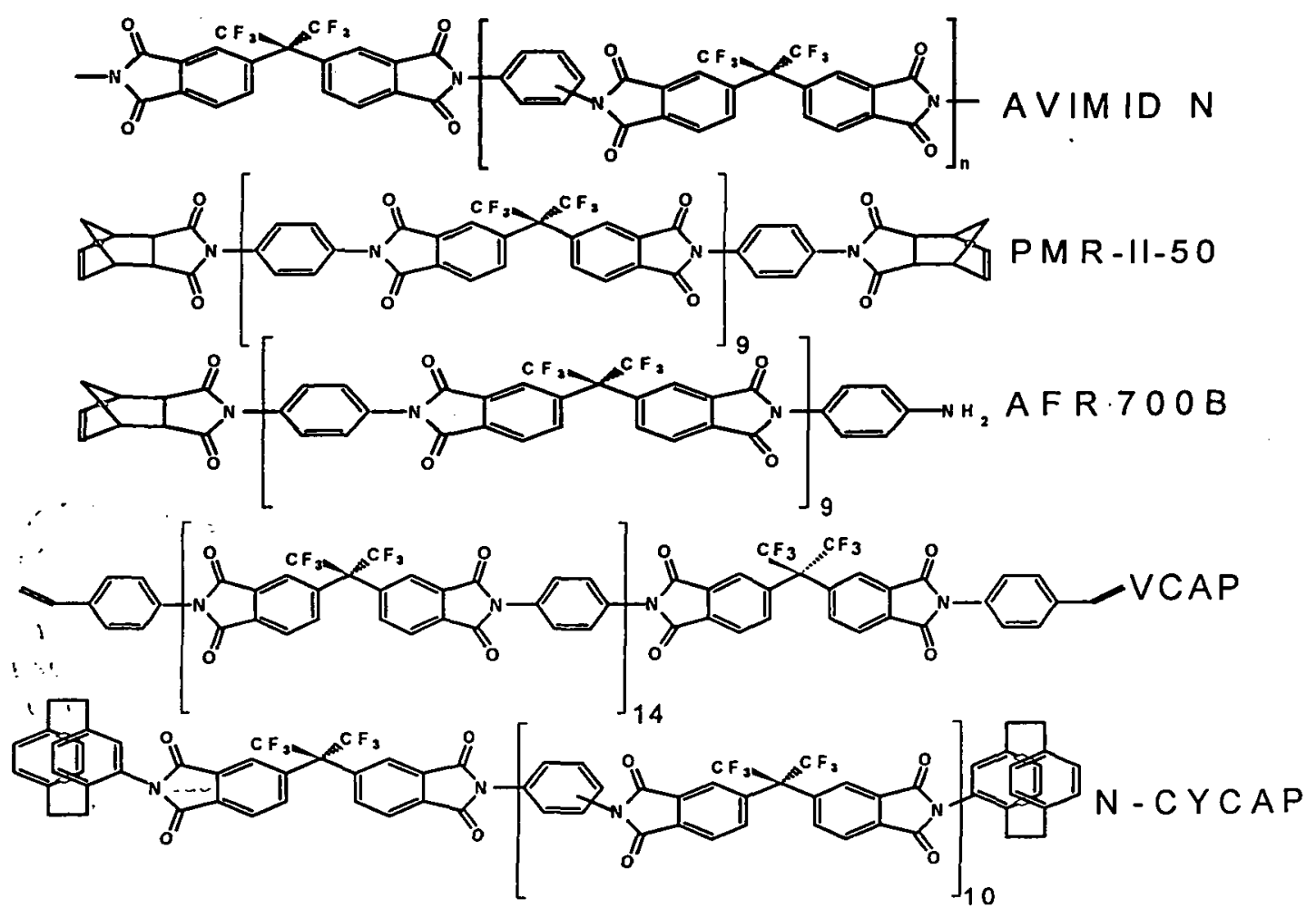

Figure 1 Polyimides aged at $371^{\circ} \mathrm{C}$.

ical analyses were performed with a DuPont Instruments 943 TMA that employed a scan rate of $10^{\circ} \mathrm{C} /$ min on neat resin disks. Differential scanning calorimetry was carried out on imidized molding powders in a DuPont Instruments Model 910 DSC cell with a scan rate of $10^{\circ} \mathrm{C} / \mathrm{min}$ under ambient air. Paired-ion HPLC analyses were done with a Beckman System Gold chromatograph using a Hamilton PRP-1 column and a gradient mixture of acetonitrile (with water as the solvent system). The water for HPLC analysis was purified with a Millipore Milli$Q$ system and subsequently treated with tetrabutylammonium perchlorate as a paired-ion reagent. Hardened steel dies were purchased from F. Carver. A Wabash press equipped with a $30.5 \times 30.5 \mathrm{~cm}$ high-temperature platens was used to compression mold the resin disks. A Blue M Model \#POM-6680E3 was used to age the disks in air.

\section{Materials}

Avimid- $\mathrm{N}$ resin samples, $p$-phenylene diamine ( $p$ PDA), and $m$-phenylenediamine ( $m$-PDA) were supplied by DuPont Company Advanced Materials. AFR700B molding powder (lot nos. 308801 and 217501) were purchased from HyCOMP Inc. 4Amino [2.2] paracyclophane was synthesized ac- cording to an improved method. ${ }^{3}$ The following chemicals were used as received: reagent grade glacial acetic acid (Fisher), reagent grade acetic anhydride (Aldrich) , 4,4'-( hexafluoroisopropylidene) diphthalic anhydride (HFDA) (Hoechst Celanese), tetrabutylammonium perchlorate (Kodak), monomethyl cis-5-norbornene-endo-2,3-dicarboxylate (Pharm-Eco Laboratories), $p$-aminostyrene (Polysciences Inc.), mono-Coat E63FF release agent (Chem-trend) . 4,4'- (Hexafluoroisopropylidene) diphthalic anhydride dimethyl ester diacid (HFDE) was prepared by refluxing HFDA in methanol for 2 $h$ under a nitrogen atmosphere such that the final concentration of HFDE was $50 \mathrm{wt} \%$. The purity of HFDE was determined by HPLC analysis.

\section{Synthesis of PMR-II-50, VCAP-75, and N-CYCAP Molding Powders}

The number of moles of monomeric reactants in PMR-II-50 was governed by the ratio $n: n+1: 2$, where $n, n+1$, and 2 are the number of moles of dianhydride (or diacid diester), diamine, and end cap, respectively, although the number of moles of monomeric reactants in VCAP-75 and N-CYCAP was governed by the ratio $n: n+1: 2$, where $n, n$ +1 , and 2 are the number of moles of diamine, dian- 
hydride (or diacid diester), and end cap, respectively. Both PMR-II-50 and VCAP-75 use HFDE as the diacid diester. N-CYCAP uses HFDA as the dianhydride. The $n$ values for PMR-II-50, VCAP75 , and N-CYCAP are 9, 14, and 10, respectively.

\section{PMR-II-50}

To a solution of HFDE ( $4.53 \mathrm{~g}, 8.9 \mathrm{mmol})$ in methanol we added $p$-PDA $(1.07 \mathrm{~g}, 9.9 \mathrm{mmol})$ and nadic acid ester $(0.389 \mathrm{~g}, 1.98 \mathrm{mmol})$. This mixture was gently heated to reduce the methanol content and resulted in a viscous gum that was further heated in an air oven at $210^{\circ} \mathrm{C}$ for $2 \mathrm{~h}$.

\section{VCAP-75}

To a solution of HFDE ( $4.84 \mathrm{~g}, 9.5 \mathrm{mmol})$ in methanol was added $p$-PDA $(0.92 \mathrm{~g}, 8.5 \mathrm{mmol})$ and $p$ aminostyrene $(0.15 \mathrm{~g}, 1.26 \mathrm{mmol})$. This mixture was gently heated to reduce the methanol content and resulted in a viscous gum that was further heated in an air oven at $210^{\circ} \mathrm{C}$.

\section{N-CYCAP}

To a finely dispersed mixture of HFDA ( $4.06 \mathrm{~g}, 9.15$ $\mathrm{mmol})$ and glacial acetic acid $(50 \mathrm{~mL})$ was added p-PDA (0.88 g, $8.15 \mathrm{mmol})$ and 4-amino [2.2] paracyclophane $(0.37 \mathrm{~g}, 1.6 \mathrm{mmol})$. The reaction mixture was refluxed. Initially, the reaction mixture separated into two phases. However, after $30 \mathrm{~min}$ the mixture became a clear amber solution. The homogeneous solution persisted for approximately 15 min before forming a precipitate. Refluxing was continued for an additional 12-16 h. Acetic anhydride $(6 \mathrm{~mL})$ was added to the slurry and stirred for an additional $2-3 \mathrm{~h}$ while refluxing. The reaction was cooled to room temperature and poured into a beaker containing ice water $(150 \mathrm{~mL})$ and stirred for $30 \mathrm{~min}$. The mixture was filtered, and the molding powder was washed with cold water $(3 \times 150$ $\mathrm{mL}$ ) and air dried. The prepolymer was then vacuum dried at $100^{\circ} \mathrm{C}$ overnight. Typical yields ranged from 95 to $100 \%$.

\section{Processing Polyimide Molding Powders and Aging of Neat Resins}

A cylindrical 2.54-cm hardened-steel mold equipped with a thermocouple was sprayed with a high-temperature release agent (monocoat $\mathrm{E} 63 \mathrm{FF}$ ) and dried at room temperature for $20 \mathrm{~min}$. Sheets of Kapton (0.5-mm thick) were sprayed with release agent and cut to fit in the mold. The Kapton was placed in the mold on the top and bottom of the molding powder. The mold was charged with approximately $1.3 \mathrm{~g}$ of prepolymer and placed in a preheated $\left(380^{\circ} \mathrm{C}\right)$ press. When the temperature of the mold reached approximately $230^{\circ} \mathrm{C}, 6.9 \mathrm{MPa}$ was applied. The temperature was increased from 230 to $370^{\circ} \mathrm{C}$ over $7 \mathrm{~min}$ and held at $370^{\circ} \mathrm{C}$. After $2 \mathrm{~h}$, the mold was cooled to $200^{\circ} \mathrm{C}$, then the pressure was released, and finally, the resin disk was removed. No sample weight loss was observed during the molding process. All resins were postcured at $371^{\circ} \mathrm{C}$ in air for $16 \mathrm{~h}$. Samples were predried at $135^{\circ} \mathrm{C}$ in air for $1 \mathrm{~h}$ and then placed in a desiccator. Once the postcured resins were cooled to $25^{\circ} \mathrm{C}$, they were weighed and then placed in the air oven. The samples were aged for $400 \mathrm{~h}$ at $371^{\circ} \mathrm{C}$. All of the resins remained in the oven for the 400-h period, that is, weight losses were not recorded at periodic intervals. After aging, the samples were placed in a dessicator and cooled to $25^{\circ} \mathrm{C}$. The final weight loss values were calculated as follows: the weight of resins after postcuring minus the weight of resin after $400 \mathrm{~h}$ aging equals the weight of resin remaining.

\section{RESULTS AND DISCUSSION}

Each disk from each polymer was split into eight equally sized samples. We partitioned the tray into four locations to provide a valid comparison of percent weight losses among the resins that experienced similar aging conditions. Each location was 3 slots by 7 slots, that is, 21 slots. For a given polymer-disk combination, two samples were randomly assigned to each of the four rectangular locations. This procedure produced 20 samples per location ( 5 polymers $\times 2$ disks/polymers $\times 2$ samples/disks). The resulting 20 samples in a given location were randomly allocated to the 21 slots (Fig. 2). In our analysis, the percent weight losses were consistently different, for a given resin pair, from location to location ( $\mathrm{Ta}$ ble I).

Least squares was used to fit the following model:

$$
\begin{aligned}
y_{i j k l}=\mu+R_{i}+L_{j}+ & R L_{i j} \\
& +B_{k(i)}+L B_{j k(i)}+\varepsilon_{l(i j k)}
\end{aligned}
$$

where $y_{i j k l}$ is \% weight loss; $\mu$ is overall constant; $R_{i}$ is fixed polymer effect; $L_{j}$ is fixed location effect; $B_{k(i)}$ is random molding powder within polymer effect; $R L_{i j}$, is fixed resin by location interaction effect; $L B_{j k(i)}$ is random location by molding powder interaction effect within polymer; $\varepsilon_{l(i j k)}$, is random error 


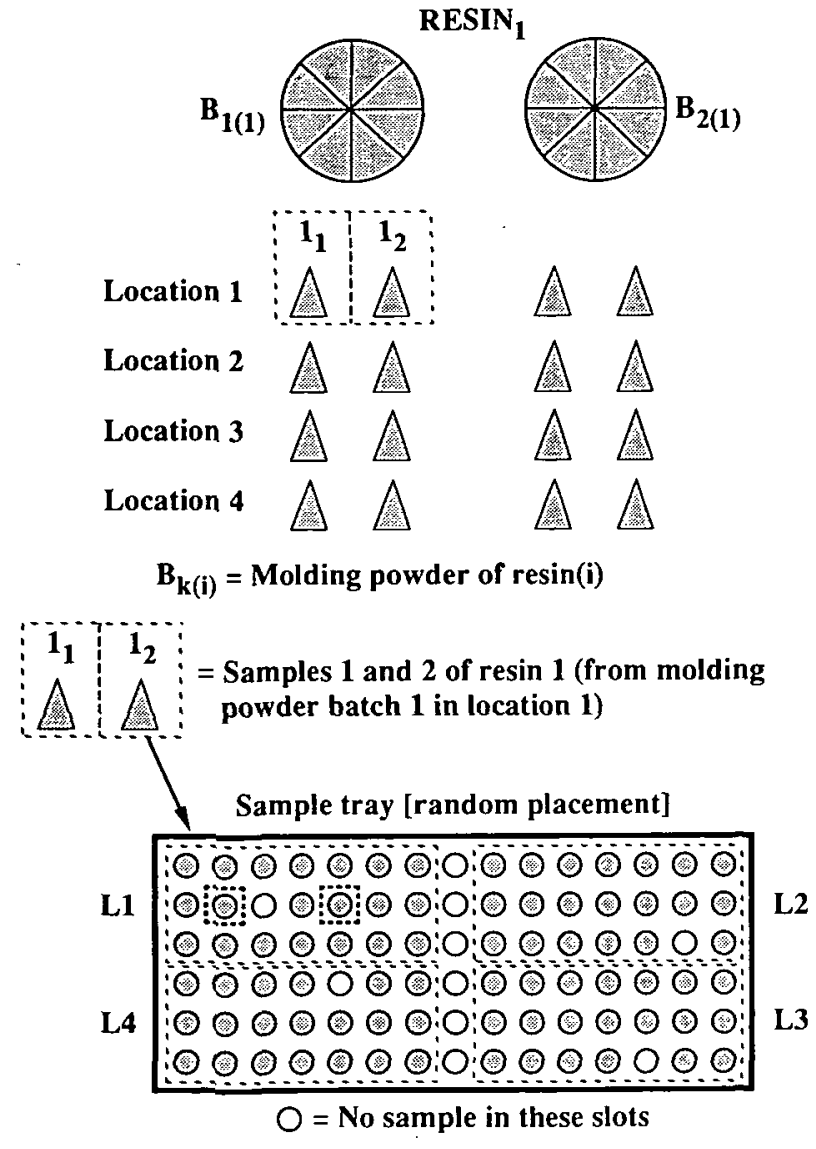

Figure 2 Experimental layout.

term; in which subscripts $i=1, \ldots, 5$ is polymer number; $j=1, \ldots, 4$ location number; $k=1,2$ is molding powder number; and $l=1,2$ sample number.

In this model, molding powders 1 and 2 from polymer 1 are different from molding powders 1 and 2 from polymer 2, etc. Sample numbers 1 and 2 from a given polymer, molding powder, and location combination are different from samples 1 and 2 from a different polymer, molding powder, and location combination. The variables $\varepsilon_{l(i j k)}, B_{k(i)}$ and $L B_{j k(i)}$ were treated as normal random variables with zero means and variances $\sigma_{\varepsilon}^{2}, \sigma_{B}^{2}$, and $\sigma_{L B}^{2}$.

The normal probability plot (used to evaluate our normal theory assumption) and residual plot (used to evaluate the constant variance assumption for every $y_{i j k l}$ ) both detected violations of the corresponding assumptions (Fig. 3). Hence, a natural logarithm transformation was applied to the $y_{i j k l}$ 's, and least squares was used to fit the model given by eq. (2). The resulting normal probability plot showed a negligible departure from the assumed normal theory, and the residual vs. the predicted plot revealed a constant variance (Fig. 4). Thus, our analyses are applicable on the natural log scale $(\ln )$.

Table II contains development of the expected mean squares (MS) for the model

$$
\begin{aligned}
\ln \left(y_{i j k l}\right)=\mu+R_{i}+ & L_{j}+R L_{i j} \\
& +B_{k(i)}+L B_{j k(i)}+\varepsilon_{l(i j k)} .
\end{aligned}
$$

Table II is derived from the rules Neter et al. ${ }^{4}$ described, and indicates how to form test statistics applicable to the questions motivating this article. Table III presents an analysis of variance (ANOVA) obtained using the least squares methodology. We see that the ANOVA given in Table III contains estimates of the corresponding expected MS given in Table II. Thus, to test the null hypothesis $\left[\mathrm{H}_{0}\right.$ : Each of the 10 polymer differences are the same for each location $\left(R L_{i j}=0\right.$ for every $\left.i j\right)$.] against the alternate hypothesis $\left[\mathrm{H}_{A}\right.$ : There exists at least one difference among polymers that is not the same from location to location ( $R L_{i j} \neq 0$ for at least one $i j$ combination ).], the appropriate test statistic $(F)$ is indicated by Table II to be

$$
F_{12,15}=\frac{\text { MS location } \times \text { polymer }}{\text { MS location } \times \text { powder }(\text { polymer })} .
$$

For example,

Table I Raw Percent Weight Loss after $371^{\circ} \mathrm{C}$ Isothermal Aging

\begin{tabular}{cccccc}
\hline Location & Avimid-N & AFR700B & VCAP-75 & N-CYCAP & PMR-II-50 \\
\hline 1 & 9.7 & 26.7 & 26.2 & 25.2 & 28.8 \\
2 & 9.8 & 23.6 & 23.1 & 24.7 & 25.2 \\
3 & 8.9 & 21.9 & 22.7 & 22.2 & 24.3 \\
4 & 10.7 & 23.5 & 24.5 & 26.3 & 30.8 \\
Average (1-4) & 9.8 & 23.9 & 24.2 & 24.6 & 27.2 \\
\hline
\end{tabular}

Means averaged across locations. Aging performed in a Blue M, Model CW160E-MP with a temperature capability up to $704^{\circ} \mathrm{C}$. Environment for $371^{\circ} \mathrm{C}$ testing: 1 atm air. 


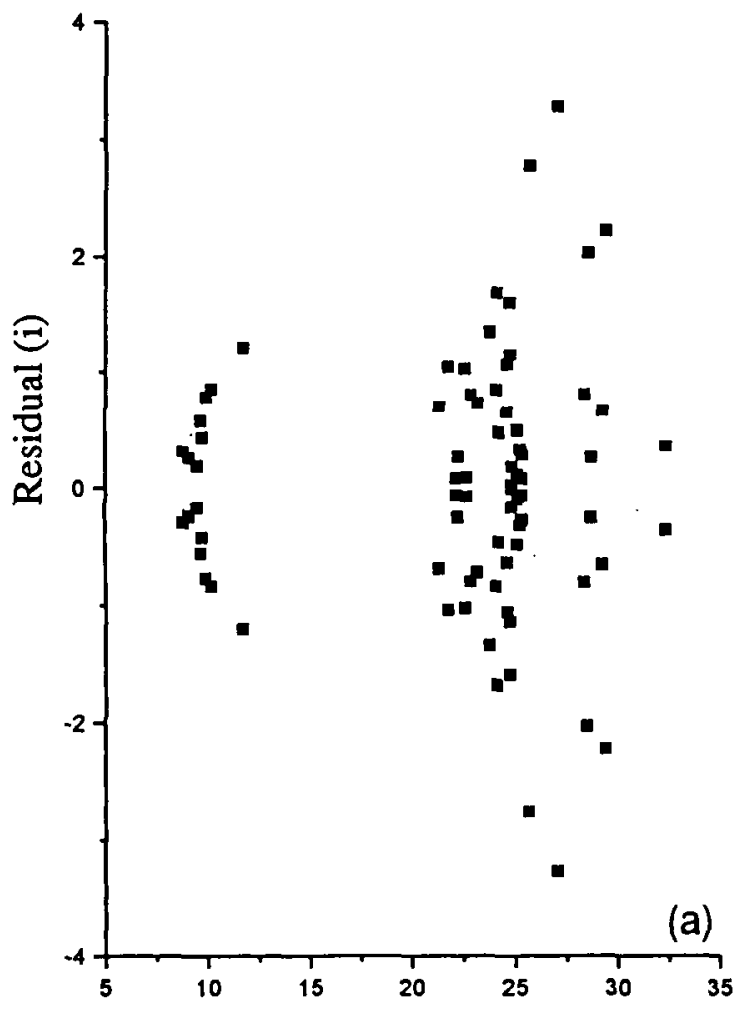

Predicted Percent Weight Loss

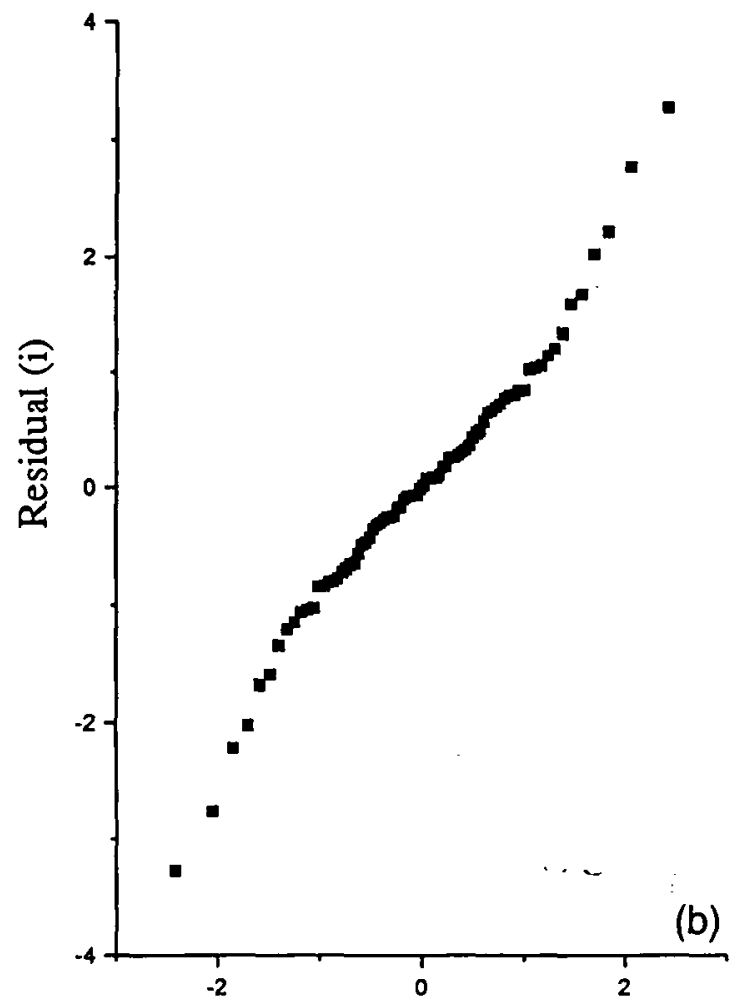

Standard Normal Random Variable

Figure 3 (a) Residual and (b) normal probability plots using the untransformed data.

$$
F_{12,15, \text { calc }}=\frac{0.00919039}{0.00521}=1.7639
$$

For a level of significance $\alpha=0.05$, we require $F_{(12,15, \alpha=0.05)}=2.48$. Because $F_{(12,15, \text { calc })}<2.48$, we do not have strong evidence to conclude that there exists at least one difference among polymers that is not the same from location to location $\left(\mathrm{H}_{A}\right)$. Instead, we conclude that there is no interaction of location with polymer type $\left(\mathrm{H}_{0}\right)$. In fact, the $p$ value (observed significance level) $>0.10$.

Because polymer differences are consistent from location to location, it is valid to average the polymer log percent weight losses across locations before comparing them to one another. Therefore, to test this null hypothesis $\left(\mathrm{H}_{0}\right.$ : All polymers are the same with respect to average log percent weight loss.) against an alternate hypothesis $\left(\mathrm{H}_{A}\right.$ : At least one polymer is different from one or more polymers with respect to average log percent weight loss.), we use Table II to identify the appropriate statistic as

$$
F_{4,5}=\frac{\text { MS polymer }}{\text { MS powder (polymer) }} \text {. }
$$

For example,

$$
F_{4,5, \text { calc }}=\frac{2.842411}{0.00924}=307.6202 \text {. }
$$

For a level of significance $\alpha=0.05$, we require $F_{(4,5, \alpha=0.05)}=5.19$. Because $F_{(4,5, \text { calc })}>5.19$, we have strong evidence to conclude that there exists at least one difference among the true average log percent weight losses for the respective polymers $\left(\mathrm{H}_{A}\right)$. The $p$ value $\ll 0.01$.

Fisher's protected least significant difference $(\mathrm{LSD})^{5}$ and Tukey's honest significant difference $(\mathrm{HSD})^{4}$ are the two multiple comparison methods we applied to evaluate the differences in percent weight loss from polymer to polymer (on the In scale) (Table IV). A 0.05 significance level was chosen for each method. Differences in the mean of the logs among the five polymers are displayed with material footnoted Table IV. Fisher's protected LSD grouped the polymers as indicated by footnote $a$. With the more conservative Tukey's HSD, we observed the grouping illustrated with footnote $b$. 


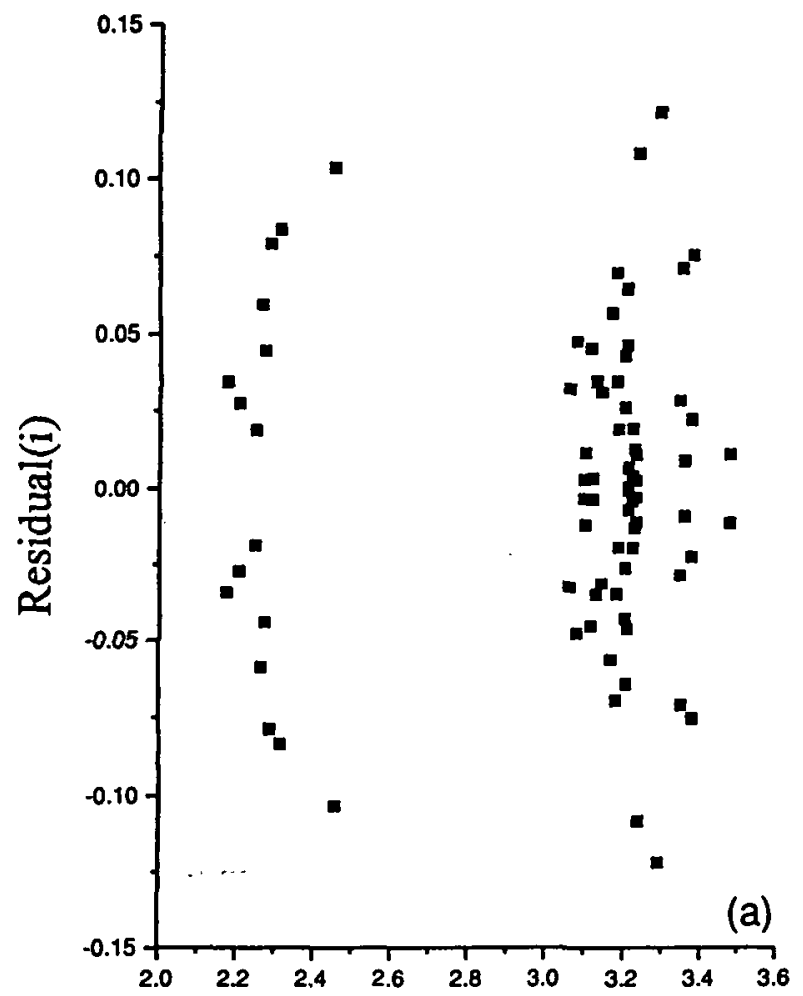

Predicted $\ell$ n Percent Weight Loss

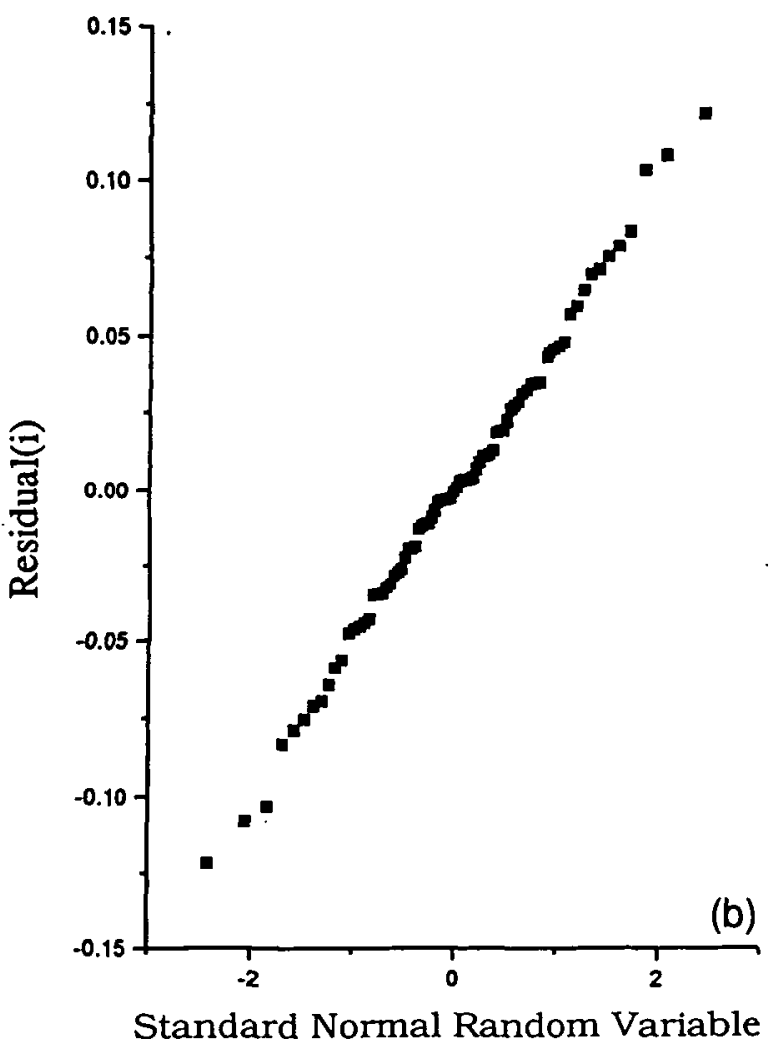

Figure 4 (a) Residual and (b) normal probability plots using the transformed data.

Resins are grouped together when there is no significant difference in the weight loss among them on the natural log scale according to the method used. We conclude that there is a $5 \%$ chance that we have made at least one mistake in the seven significant differences detected using the LSD method, and in the four significant differences using the HSD method (footnotes $a$ and $b$ in Table IV).

The only difference in Tukey's HSD and Fisher's protected LSD is that PMR-II-50 is judged to be in the same group as AFR700B, VCAP-75, and N-CYCAP with Tukey's HSD (footnote b, Table IV), whereas the LSD method identified that an important difference existed between PMR-II-50 and the other polymers (footnote a, Table IV). Another graphic representation of Fisher's protected LSD and 'Tukey's HSD methods can be seen in Figures 5 and 6 , respectively. The conclusions drawn from Figures 5 and 6 are mathematically equivalent to those drawn from Table IV(b). This corresponds to

Table II Expected Mean Squares for Stated Model [Eq. (2)]

\begin{tabular}{lcl}
\hline \multicolumn{1}{c}{ Source } & Degrees of Freedom & Expected Mean Square \\
\hline $\begin{array}{l}\text { Corrected total } \\
\text { Polymer }\end{array}$ & 79 & \\
Location & 4 & $\left(\frac{16}{4}\right) \sum_{i=1}^{5} R_{i}^{2}+8 \sigma_{B}^{2}+\sigma^{2}$ \\
Location $\times$ polymer & 3 & $\left(\frac{20}{3}\right) \sum_{j=1}^{4} L_{j}^{2}+2 \sigma_{L B}^{2}+\sigma^{2}$ \\
Powder (polymer) & 12 & $\left(\frac{4}{12}\right) \sum_{i=1}^{5} \sum_{j=1}^{4} R L_{i j}^{2}+2 \sigma_{L B}^{2}+\sigma^{2}$ \\
Location $\times$ powder (polymer) & 5 & $8 \sigma_{B}^{2}+\sigma^{2}$ \\
Error & 15 & $2 \sigma_{L B}^{2}+\sigma^{2}$ \\
\hline
\end{tabular}


Table III Analysis of Variance for Fitted Model Using ln(y)

\begin{tabular}{lccc}
\hline \multicolumn{1}{c}{ Source } & Degrees of Freedom & Sum of Squares & Mean Squares \\
\hline Corrected total & 79 & 12.096 & 2.8424 \\
Polymer & 4 & 11.369 & 0.09888 \\
Location & 3 & 0.29665 & 0.00919 \\
Location $\times$ polymer & 12 & 0.11028 & 0.00924 \\
Powder (polymer) & 15 & 0.04623 & 0.00521 \\
Location X powder (polymer) & 1 & 0.07816 & 0.00488 \\
Error & 40 & 0.19519 & \\
\hline
\end{tabular}

the underscoring in Table IV(a). If the bounds do not overlap in Figures 5 and 6 , significant differences exist above and beyond that due to randomness among the means of the natural log percent weight loss for each of the resins.

Tukey's HSD method is more conservative because its interpretation implies that not only is there at most a $5 \%$ chance that we have made at least one mistake in the four identified differences, but that we have a $95 \%$ chance or confidence that all the $\left(\begin{array}{l}5 \\ 2\end{array}\right)=10$ intervals for the differences in means of the log percent weight losses actually include the true differences. This cannot be said using Fisher's protected LSD. The raw mean of percent weight loss for each of the polymers averaged across locations and for each location are shown in Table I.

The 10 HSD 95\% intervals mentioned in the previous paragraph take on the form

$$
\hat{D} \pm T \cdot s\{\hat{D}\}
$$

$\hat{D}$ is the estimated difference in the average log per- cent weight loss, after averaging across locations, for a given pair of polymers. The estimated standard deviation of $\hat{D}$ is

$$
s\{\hat{D}\}=\left[\frac{2}{16}(\mathrm{MS} \text { powder (polymer) })\right]^{1 / 2} .
$$

The constant $T$ is available from statistical tables. (See Neter et al. ${ }^{4}$ for details of Tukey's HSD multiple comparison methods.) Table $\mathrm{V}$ contains the 10 intervals constructed using Tukey's HSD 95\% confidence interval methodology.

Now, one might ask about the interpretation of our results in terms of the raw data (percent weight loss). We gain insight into this question by backtransforming with the exponential transformation. Because our normal probability plot revealed logs of the percent weight losses to be normally distributed, we are dealing with the lognormal distribution; that is, $\ln \left(y_{i j k l}\right)$ is normally distributed. Denoting $\delta$ as the true mean of a lognormally distributed random variable, $\delta$ is also the median of the lognormally distributed random variable because of symmetry.

Table I.V Comparison of Fisher's Protected LSD Test and Tukey's Honest Significant Difference Test

(a) Mean of ln Averaged Over Locations For Each Resin ${ }^{a, b}$

\begin{tabular}{cccccc}
\hline Resin & Avimid-N & AFR700B & VCAP-75 & N-CYCAP & PMR-II-50 \\
\hline Mean of ln & 2.278 & 3.172 & 3.185 & 3.198 & 3.301
\end{tabular}

(b) Differences of Means ${ }^{c}$

$\begin{array}{lllll}\text { Avimid-N } & 0.893^{\mathrm{a}, \mathrm{b}} & 0.906^{\mathbf{a}, \mathrm{b}} & 0.920^{\mathrm{a}, \mathrm{b}} & 1.022^{\mathrm{a}, \mathrm{b}} \\ \text { AFR700B } & & 0.013 & 0.026 & 0.129^{\mathbf{a}} \\ \text { VCAP-75 } & & & 0.014 & 0.116^{\mathrm{a}} \\ \text { N-CYCAP } & & & & 0.103^{\mathrm{a}}\end{array}$

PMR-II-

50

areak in underscoring indicates an important statistical difference has been determined using Fisher's protected LSD: LSD 0.05 $=0.087$.

${ }^{b}$ Break in underscoring indicates an important statistical difference has been determined using Tukey's HSD: $\mathrm{HSD}_{0.05}=0.188$.

${ }^{\mathrm{c}}$ After transformation. 


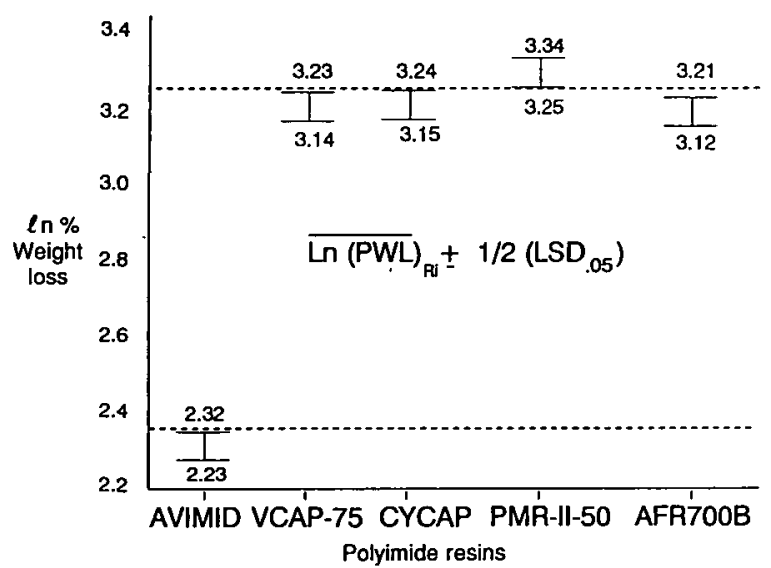

Figure 5 Fisher's protected least significant difference test.

Furthermore, the ln transformation is monotonic, that implies that if the median of the original variable $(y)$ is, for example, $m$, the median of the transformed variable $(\ln y)$ is $\ln (m)$. Hence, $\delta=\ln (m)$. Back-transforming with the exponential function gives $\exp (\delta)=m$, the median of the untransformed (or original) variable. To continue, if we let $\delta_{i}$ $=\ln \left(m_{i}\right)$, where $\delta_{i}$ is the mean of the $i^{\text {th }}$ lognormally distributed population and $m_{i}$ is the median of the respective untransformed population, we have

$$
\delta_{i}-\delta_{j}=\ln \left(m_{i}\right)-\ln \left(m_{j}\right), \quad i \neq j .
$$

Thus, using the exponential transformation, we obtain

$$
\begin{aligned}
\exp \left(\delta_{i}-\delta_{j}\right)=\exp \left[\ln \left(m_{i}\right)-\ln \left(m_{j}\right)\right] & \\
& \text { or } \exp \left(\delta_{i}-\delta_{j}\right)=m_{i} / m_{j} .
\end{aligned}
$$

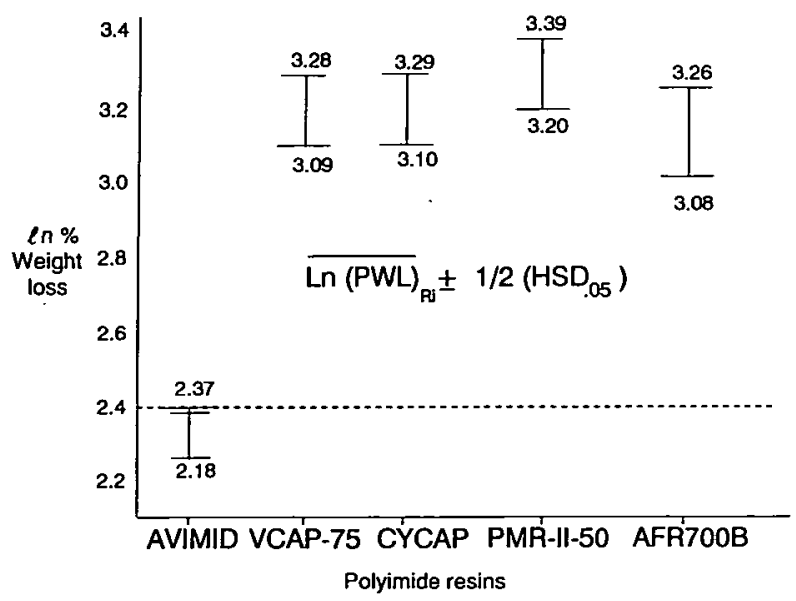

Figure 6 Tukey's honest significant difference test.
Table V HSD 95\% Family Confidence Intervals for True Difference in Average Log Percent Weight Losses ${ }^{\mathrm{a}}$

\begin{tabular}{cc}
\hline Polymer Difference $^{b}$ & Confidence Interval \\
\hline $5-1$ & $(0.7051,1.082)$ \\
$2-1$ & $(0.7179,1.094)$ \\
$3-1$ & $(0.7317,1.108)$ \\
$4-1$ & $(0.8343,1.211)$ \\
$2-5$ & $(-0.1754,0.2011)$ \\
$3-5$ & $(-0.1617,0.2148)$ \\
$4-5$ & $(-0.0590,0.3175)$ \\
$3-2$ & $(-0.1745,0.2020)$ \\
$4-2$ & $(-0.0718,0.3046)$ \\
$4-3$ & $(-0.0856,0.2909)$ \\
\hline
\end{tabular}

${ }^{a} \delta_{i}-\delta_{j}$, corresponds to the respective $\left(\begin{array}{l}5 \\ 2\end{array}\right)=10$ polymer differences.

${ }^{\mathrm{b}}$ Polymers: Avimid-N $=1, \mathrm{VCAP}-75=2, \mathrm{~N}-\mathrm{CYCAP}=3$, PMR-II-50 $=4$, AFR700B $=5$.

Now, $m_{i} / m_{j}$ is the ratio of medians from respective populations in terms of the untransformed data. Turning to Table V, we use the exponential transformation of the end points from each of the respective intervals. The resulting confidence intervals estimate the ratio of the corresponding polymer median percent weight losses (with the same group or family confidence level equal to $95 \%$ ). These intervals are given in Table VI.

There is one final yet important note regarding our findings. Deming ${ }^{6-8}$ and, more recently, Hahn and $M e e k e{ }^{9}$ have detailed the important distinction between an enumerative and an analytic study. Our study is considered analytic. Hence, our results require the critical assumption that molding powders

Table VI HSD 95\% Family Confidence Intervals for Ratio of Median Percent Weight Losses ${ }^{a}$

\begin{tabular}{cc}
\hline Polymer Ratio $^{b}$ & Confidence Interval \\
\hline $5 / 1$ & $(2.024,2.951)$ \\
$2 / 1$ & $(2.050,2.986)$ \\
$3 / 1$ & $(2.079,3.028)$ \\
$4 / 1$ & $(2.303,3.357)$ \\
$2 / 5$ & $(0.8391,1.223)$ \\
$3 / 5$ & $(0.8507,1.240)$ \\
$4 / 5$ & $(0.9427,1.374)$ \\
$3 / 2$ & $(0.8399,1.224)$ \\
$4 / 2$ & $(0.9307,1.356)$ \\
$4 / 3$ & $(0.9180,1.338)$ \\
\hline
\end{tabular}

a $m_{i} / m_{j}$, corresponding to the respective $\left(\begin{array}{l}5 \\ 2\end{array}\right)=10$ polymer ratios.

${ }^{b}$ Polymers: Avimid-N $=1$, VCAP-75 $=2, \mathrm{~N}-\mathrm{CYCAP}=3$, PMR-II-50 $=4$, AFR700B $=5$. 
made in the future vary in the same manner as those selected for this study and that the procedure for making disks varies in the same manner in the future as for this study. This complies with the requirement noted by Hahn and Meeker" ${ }^{10}$ that "analytic studies require the critical added assumption that the process about which one wishes to make inferences is statistically identical to that from which the sample was selected."

\section{SUMMARY AND CONCLUSIONS}

A method was developed to reliably determine if differences exist in the thermal oxidative stability of resins. In addition to quantifying these differences by percent weight loss, the design of the experiment enabled us to correctly adjust for temperature gradients in the oven and the variability that exists within a resin type (i.e., molding powder-molding powder, disk-disk, and within a given disk ). Finally, although two methods were used to determine differences in thermal oxidative stability, the only resin that was noticably different (lowest weight loss) in both analyses was Avimid-N. We believe that this difference can be attributed to two factors. (1) Although all of the other polyimides in this study, which were addition-curing polyimides, have end caps, Avimid- $\mathrm{N}$ does not. These end caps have aliphatic carbons that can oxidize and contribute toward thermal oxidative weight loss. (2) Of the five polymers studied, Avimid- $\mathrm{N}$ was the only polymer not processed in our laboratories and we have no basis for comparing the processing conditions because those for Avimid-N are proprietary. However, it is well known that processing conditions contribute to the thermal oxidative stability of polymers. ${ }^{11}$

The authors wish to thank Professor H. T. David, Department of Statistics at Iowa State University, and Pro- fessor David Weeks, Department of Statistics at Oklahoma State University for their advice on the statistical modeling. In addition, we express our gratitude to Marla Schuerman for her assistance in molding the resins and Dan Scheiman for the thermal analysis studies performed on these resins. Samples of AFR700B were purchased from Dr. Joseph Reardon at HYCOMP in Cleveland, $\mathrm{OH}$. Avimid-N was supplied by Dr. Murty S. Tanikella at DuPont Advanced Composites.

\section{REFERENCES}

1. W. E. McCormack, in HITEMP Review 1992: Advanced High Temperature Engine Materials Development Program, NASA CP-10104, 1992, pp. 5.1-5.14.

2. H. Gupta, R. Baggett, and J. Caustill, in HITEMP Review 1991: Advanced High Temperature Engine Materials Development Program, NASA CP-10082, 1991, pp. 9.1-9.14.

3. J. F. Waters, J. K. Sutter, M. A. B. Meador, L. J. Baldwin, and M. A. Meador, J. Polym. Sci. Part A: Polym. Chem., 29, 1917-1924 (1991).

4. J. Neter, W. Wasserman, and M. Kutner, Applied Linear Statistical Models, 3rd ed., Irwin, Homewood, IL, 1990, pp. 580-594, 1015-1029.

5. R. G. Miller, Jr., Simultaneous Statistical Inference, 2nd ed., Springer-Verlag, New York, 1986, pp. 26, 27, 90-94.

6. W. E. Deming, J. Am. Stat. Assoc., 48, 244-255 (1953).

7. W. E. Deming, Am. Statistician, 29, 146-152 (1975).

8. W. E. Deming, in Rep. Stat. Appl. (Japanese Union of Scientists and Engineers), 23, 25-31 (1976).

9. G. J. Hahn and W. Q. Meeker, Am. Statistician, 47, 1-11 (1993).

10. G. J. Hahn and W. Q. Meeker, Am. Statistician, 47, 4 (1993).

11. K. K. Bowles, A Thermally Modified Polymer Matrix Composite Material with Structural Integrity to $371^{\circ} \mathrm{C}$, NASA TM 100922, 1988.

Received October 11, 1994

Accepted March 3, 1995 